Index (BASMI), pain visual analog scale, Beck depression scale, Beck anxiety scale, Barrat impulsiveness scale, Toronto alexithymia scale, Eating attitude test, fatigue, Ankylosing spondylitis quality of life, and Nothingam health profile were administered.

Results: The frequency of depression, anxiety and non planning impulsiveness were higher in patients with AS than in healthy controls $(p<0.05)$, although no difference was found in terms of alexithymia, fatigue, and eating attitude. Depression and anxiety were correlated with high disease activity, fatigue, impaired physical functioning, and lower quality of life in the patients with AS. Non planning impulsiveness was correlated with fatigue and lower quality of life while there was no correlation with disease activity and functional impairment. BASMI scores were not associated with psychiatric disorders.

Table 1. Demographic characteristics and Psychiatric disorders in Ankylosing spondylitis and healthy controls

\begin{tabular}{lccc}
\hline & $\begin{array}{c}\text { Ankylosing spondylitis patients } \\
(\mathrm{n}=70)\end{array}$ & $\begin{array}{c}\text { Healthy controls } \\
(\mathrm{n}=56)\end{array}$ & $\mathrm{p}$ \\
\hline Age (year) & $42.85 \pm 10.46$ & $44.75 \pm 10.04$ & 0.363 \\
Male (\%) & $57.14 \%$ & $51.78 \%$ & 0.548 \\
Beck depression score & $13.88 \pm 8.99$ & $9.78 \pm 8.34$ & $0.006^{*}$ \\
Beck anxiety score & $14.58 \pm 10.02$ & $10.53 \pm 8.99$ & $0.014^{*}$ \\
Barrat impulsiveness - attentional score & $15.68 \pm 3.25$ & $15.21 \pm 2.72$ & 0.590 \\
Barrat impulsiveness - motor score & $19.62 \pm 4.28$ & $18.92 \pm 4.23$ & 0.301 \\
Barrat impulsiveness - non planning score & $26.00 \pm 4.57$ & $24.78 \pm 3.77$ & $0.021^{*}$ \\
Toronto alexithymia score & $54.84 \pm 12.86$ & $54.32 \pm 11.12$ & 0.644 \\
Eating attitude score & $21.74 \pm 11.18$ & $22.01 \pm 13.24$ & 0.488 \\
\hline
\end{tabular}

${ }^{*} \mathrm{P}<0.05$

Conclusions: Depression and anxiety were associated with disease activation, while impulsivity frequency was increased independently of disease activity. Reducing in the quality of life and functional competence due to the psychiatric disorders indicates that, AS patients may require a psychological care approach during the follow up.

References:

[1] Anxiety and depression correlate with disease and quality-of-life parameters in Chinese patients with ankylosing spondylitis.Xu X, Shen B, Zhang A, Liu J, Da Z, Liu H, Gu Z. Patient Prefer Adherence(2016) 20;10:879-85. doi: 10.2147/PPA.S86612.

[2] Relationship between psychiatric status, self-reported outcome measures, and clinicalparameters in axial spondyloarthritis. Kilic G, Kilic E, Ozgocmen S. Medicine (Baltimore) (2014) doi: 10.1097/MD.0000000000000337.

Disclosure of Interest: None declared

DOI: 10.1136/annrheumdis-2017-eular.2629

\section{FRI0440 PRESENCE OF BONE MARROW EDEMA ON MAGNETIC RESONANCE IMAGING OF THE SACROILIAC JOINTS IN MILITARY RECRUITS BEFORE AND AFTER 6 WEEKS OF INTENSIVE PHYSICAL TRAINING}

G. Varkas ${ }^{1,2}$, M. de Hooge ${ }^{1}$, T. Renson ${ }^{1}$, P. Carron ${ }^{1,2}$, S. De Mits ${ }^{3}$, G. Souverijns ${ }^{4}$, D. Elewaut ${ }^{1,2}$, F. Van den Bosch ${ }^{1,2}$. ${ }^{1}$ Department of Rheumatology, Ghent University Hospital; ${ }^{2}$ VIB Inflammation Research Centre; ${ }^{3}$ Department of Rehabilitation Sciences and Physical Therapy, Ghent University, Gent; ${ }^{4}$ Department of Radiology, Jessa Ziekenhuis, Hasselt, Belgium

Background: Studies have shown an increase of bone marrow edema (BME) on magnetic resonance imaging (MRI), especially in feet and ankles of professional athletes and in minimally active healthy controls after mechanical stress [1]. Although this has been described for several joints and across different sport activities, information concerning BME in the sacroiliac joints (SIJ) has not been studied. In axial spondyloarthritis (AxSpA), the presence of 1 BME lesion (characteristics typical for $\mathrm{AxSpA}$ ) on 2 consecutive slices or $2 \mathrm{BME}$ lesions on 1 slice is sufficient to fulfill the definition of a positive MRI as defined by ASAS. Although this definition should only be applied on MRI of symptomatic patients with suspicion of $\mathrm{SpA}$, it is unknown whether BME lesions in healthy controls could meet this definition and therefore incorrectly be interpreted as BME in the context of SpA.

Objectives: Study the effect of intense physical training in healthy subjects on the presence of BME on MRI-SIJ, by investigating whether healthy subjects meet the ASAS definition of a positive MRI and whether this is modulated by mechanical stress.

Methods: Twenty-two military recruits underwent a MRI-SIJ before and after 6 week of intense and uniform physical training. BME lesions were scored by 3 trained readers ( $\mathrm{MdH}, \mathrm{GV}$ and TR) blinded for time sequence and clinical findings. Additionally, the agreement with the definition of a positive MRI defined by ASAS was evaluated. Regarding the number of lesions and fulfillment of the ASAS definition of positive MRI, a consensus was made by agreement of 2 out of 3 readers. Results: In total, $86.4 \%$ (19/22) asymptomatic recruits were male (mean age of $25.0 \pm 0.8$ years). At baseline, $40.9 \%(9 / 22)$ of recruits presented with at least one BME lesion, whereas this number increased to $50.0 \%(11 / 22)$ at week 6 . Indeed, 3 recruits developed BME over time, whereas in one recruit the BME lesions disappeared over time. The mean number of BME lesions was $1.0( \pm 0.3)$ at baseline, compared to $1.9( \pm 0.7)$ at week 6 . Median (25th, 75th percentile) BME lesions were $0.0(0.0,2.25)$ and $0.5(0.0,3.0)$ at respectively baseline and week
$6(P=0.109)$. Mean change in BME lesions was $0.9( \pm 0.6)$. When applying the ASAS definition of a positive MRI, BME was present in $22.7 \%$ (5/22) of recruits at baseline, and this increased to $36.4 \%$ at follow up, of which an additional 4 initially MRI negative recruits became MRI positive and one recruit no longer fulfilled the definition.

Conclusions: In this small exploratory study we could not find a statistically significant difference in BME on MRI-SIJ after 6 weeks of training. However, over $1 / 5$ of asymptomatic recruits displayed BME lesions, that would meet the ASAS definition of a positive MRI, increasing to more than $1 / 3$ at follow up. Thus, in young active patients, the interpretation of BME lesions should be cautious.

References:

[1] Kornaat PR, Van de Velde SK. Bone marrow edema lesions in the professional runner. The American journal of sports medicine 2014:42(5):1242-6.

Acknowledgements: ASAS research grant 2017.

Disclosure of Interest: None declared

DOI: 10.1136/annrheumdis-2017-eular.5947

\section{FRI0441 NECK PAIN IN ANKYLOSING SPONDYLITIS: FOCUS ON ACTIVE INFLAMMATION AT THE CRANIOCERVICAL JUNCTION ON MRI}

G. Slobodin ${ }^{1}$, I. Rosner ${ }^{1}$, A. Awisat ${ }^{1}$, D. Rimar ${ }^{1}$, A. Shpigelman ${ }^{2}$, D. Militianu ${ }^{3}$ ${ }^{1}$ Rheumatology; ${ }^{2}$ Orthopedic Surgery, Bnai Zion Medical Center;

${ }^{3}$ Radiology/Muskulosceletal Imaging, Rambam Medical Center, haifa, Israel

Background: A wide spectrum of structural changes in the elements of craniocervical junction in patients with ankylosing spondylitis (AS) has been recently described in a retrospective study using computed tomography [1]. The clinical significance of these findings requires further elaboration.

Objectives: To explore and describe inflammatory MR imaging findings in the craniocervical junction in patients with AS and neck pain.

Methods: Eighteen patients with AS and continuing neck pain, as well as 9 patients with fibromyalgia of the same age and similar level of severity of neck pain, who served as a control group, underwent relevant rheumatologic examination, X-ray of cervical spine and MRI study, which included STIR, CUBE T2, FSE and FSE FAT SAT sequences before and after administration of gadolinium.

Results: In the AS group, 12 males and 6 females diagnosed by $1984 \mathrm{New}$ York criteria, of median age 40.5 years (range 31-61 years) and median disease duration of 8 (range 1-35) years, with 13 under treatment with anti-TNF agents were studied. All patients suffered from neck pain, with median VAS of 7 (range 2.5-10). Range of neck spine motion was limited in all but 3 patients. Seven of 18 patients had evidence of cervical syndesmophytes on X-ray. In addition to expected findings of syndesmophytes, active inflammatory lesions were seen in MR imaging in two of 18 patients with AS and in none with fibromyalgia (Fig. 1). Both AS patients with positive MRI were on anti-TNF therapy during the study and did not have syndesmophytes at the cervical spine as also by X-ray films.

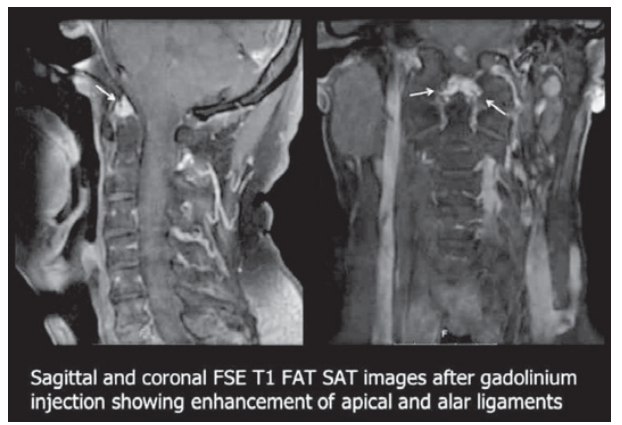

Conclusions: Active inflammation of both entheses and joints of the craniocervical junction was demonstrated by MRI in some patients with AS and persistent neck pain. Active lesions at the craniocervical junction should be included in the differential diagnosis of neck pain in AS.

\section{References:}

[1] Slobodin G, Shpigelman A, Dawood H, Rimar D, Croitoru S, Boulman N, Rozenbaum M, Kaly L, Rosner I, Odeh M. Craniocervical junction involvement in ankylosing spondylitis. Eur Spine J. 2015 Dec;24(12):2986-90.

Disclosure of Interest: None declared

DOI: 10.1136/annrheumdis-2017-eular.5818

\section{FRI0442 IDENTIFICATION OF ENTHESITIS AT THE ACHILLES TENDON INSERTION IN PATIENTS WITH ANKYLOSING SPONDYLITIS USING DIGITAL RADIOGRAPHY}

I. Sung, S.-J. Kim. Orthopedic Department, Hanyang University Medical Center, SEOUL, KOREA, Seoul, Korea, Republic Of

Background: Posterior heel pain is a common symptom in the foot and ankle region, with many different causes that need to be distinguished by differential diagnosis. Among them is ankylosing spondylitis (AS), in which enthesitis of 
the heel is common and occasionally is responsible for their initial symptom to seek clinics. An early or timely recognition of active enthesitis of AS from simple radiographs comes to be relevant issue.

Objectives: The purpose of current study is to assess measurement reliability and diagnostic validity for detecting the digital radiographic findings of enthesitis at the Achilles tendon insertion in patients with AS.

Methods: Current study is a blinded, matched, cross-sectional study with 44 patients (65 feet) having clinical enthesitis at the Achilles tendon insertion (Group I), and 44 healthy controls (65 feet) (Group II). Suggested findings of enthesitis including retrocalcaneal recess obliterations from retrocalcaneal bursitis, increased thickness in shadow of the Achilles tendon and posterior soft tissue at its insertion from the swellings of those soft tissues were assessed on digital radiographs of standing hindfoot lateral view, and their measurement reliabilities were determined. To investigate diagnostic validities, diagnostic odds ratio, sensitivity, specificity, positive likelihood ratio (PLR), and negative likelihood ratio (NLR) were estimated for radiographic findings of retrocalcaneal recess obliterations (RRO). For the thickness of the Achilles at its insertion (TAI) and swollen posterior soft tissue, the receiver operating characteristic (ROC) curve analysis was done.

Results: There were no significant differences between two groups in mean age, $\mathrm{BMI}$ and sex ratio. Intra- and inter-observer reliability of all measurements showed high degree of agreements $(0.786$ to 0.941$)$. The diagnostic odds ratio of RRO for detecting enthesitis was 66.0 . The sensitivity, specificity were $67.7 \%, 96.9 \%$, and PLR, NLR were 22.0, 0.33, respectively. The mean TAI of Group I and II were $6.7 \mathrm{~mm} \pm 1.79,5.01 \mathrm{~mm} \pm 0.81$, respectively ( $p$-value $<0.001)$. Area under the ROC curve of the TAI was 0.806 , and the optimal cut-off value predicting enthesitis was $5.47 \mathrm{~mm}$, and its sensitivity and specificity were both $72.3 \%$.

Conclusions: Retrocalcaneal recess obliteration and thickened shadow of Achilles tendon at its insertion and swollen posterior soft tissue on digital radiographs of standing hindfoot lateral view are regarded as the easy and useful findings for enthesitis of the posterior heel. For searching enthesitis at the Achilles insertion in patients with AS, such findings from simple radiographs showed high measurement reliability and validity.

\section{References:}

[1] Resnick D, Feingold ML, Curd J, Niwayama G, Goergen TG. Calcaneal abnormalities in articular disorders. Rheumatoid arthritis, ankylosing spondylitis, psoriatic arthritis, and Reiter syndrome. Radiology 1977;125:355-66.

[2] Freedman M, Steller D. Digital radiography of the musculoskeletal system: the optimal image. Journal of digital imaging 1995;8:37-42.

[3] Rudwaleit M, Khan MA, Sieper J. The challenge of diagnosis and classification in early ankylosing spondylitis: do we need new criteria? Arthritis and rheumatism 2005;52(4):1000-1008.

Disclosure of Interest: None declared

DOI: 10.1136/annrheumdis-2017-eular.4565

\section{FRI0443 THE EFFECT OF FIBROMYALGIA ON DISEASE ACTIVITY IN PATIENTS WITH ANKYLOSING SPONDYLITIS}

I. Shapoval, M. Stanislavchuk, K. Zaichko, L. Perebetiuk. Internal Medicine, National Pirogov Memorial Medical University, Vinnytsya, Ukraine

Background: Ankylosing spondylitis (AS) is a chronic inflammatory rheumatic disease that affects the axial skeleton and characterized by pain, stiffness and fatigue [4]. One of the frequent concomitant condition in patients with AS is fibromyalgia (FM). FM shares some common symptoms with AS. According to the many reports concomitant FM in patients with AS has been found in $5.7-41.3 \%$ cases $[1,2,3,5]$. Due to the fact that pain is a major component of the disease activity scores of the AS (Ankylosing Spondylitis Disease Activity Index (BASDAI) and Ankylosing Spondylitis Disease Activity Score (ASDAS)), concomitant FM can significantly modify the disease activity in patients with AS.

Objectives: The aim of this study was to evaluate the effect of FM on disease activity in patients with AS.

Methods: Diagnosis of AS was identified according to the modified New York criteria (1984). FM was diagnosed by ACR criteria (1990). Disease activity was assessed by BASDAI and ASDAS.

Results: 80 patients with AS were included into study (15 females and 65 males), age $(M \pm S D) 41.64 \pm 11.4$ years. Nineteen patients $(23.8 \%)$ met the criteria for $F M$. Patients with $A S$ and $A S+F M$ were representative for age and disease duration. In both groups, ESR $(37.7 \pm 18.8$ and $39.00 \pm 19.6 \mathrm{~mm} / \mathrm{h})$ was comparable, while ASDAS and BASDAI were significantly different. The disease activity according to both scores was higher in patients with AS+FM. According to the BASDAI in patients with AS disease activity was $5.20 \pm 1.4$ whereas in patients with $A S$ and FM - 7.14 \pm 1.7 ; according to the ASDAS-ESR difference in disease activity was slightly lower, but remained significant $(3.6 \pm 0.8$ vs $4.2 \pm 0.9)$.

Conclusions: The obtained data indicates that concomitant FM is a frequent condition in patients with AS. Presence of FM in patients with AS significantly modifies the disease activity determined by ASDAS. The ASDAS-ESR is more appropriate for determining the disease activity comparing to BASDAI, because included in calculation ESR diminish the distorting effect of FM.

\section{References:}

[1] Fibromyalgia in patients with axial spondyloarthritis: epidemiological profile and effect on measures of disease activity/Fausto Salaffi, Rossella De Angelis, Marina Carottiet al. Rheumatology International 2014;1103-1110.
[2] Occurrence of fibromyalgia in patients with ankylosing spondylitis. NalderilioFeijó Azevedo, Eduardo dos Santos Paiva, Lúcio Ricardo HiurkoFelippe, Ranieri Amorim Moreira. Bras J Rheumatol 2010;50:646-654.

[3] Ankylosing spondylitis functional and activity indices in clinical practice. Popescu C, Trandafir M, Bădică AM et al. Journal of Medicine and Life 2014:78-83.

[4] Global prevalence of ankylosing spondylitis. Linda E. Dean, Gareth T. Jones, Alan G. MacDonald et al. Rheumatology 2014;53:650-657.

[5] Prevalence of fibromyalgia in patients with ankylosing spondylitis Medical Journal of Dr. D.Y. Patil University 2014:338-341.

Disclosure of Interest: None declared

DOI: 10.1136/annrheumdis-2017-eular.3967

\section{FRI0444 INCIDENCE OF INFLAMMATORY BOWEL DISEASE EVENTS IN ADALIMUMAB CLINICAL TRIALS ACROSS INDICATIONS}

J.R. Curtis ${ }^{1}$, D. Elewaut ${ }^{2}$, S. Chen ${ }^{3}$, M. Hojnik ${ }^{4}$, N. Naveh ${ }^{5}$, J.K. Anderson ${ }^{3}$. ${ }^{1}$ Division of Clinical Immunology and Rheumatology, University of Alabama at Birmingham, Birmingham, United States; ${ }^{2}$ VIB Inflammation Research Center, University of Gent, Gent, Belgium; ${ }^{3}$ AbbVie Inc., North Chicago, United States; ${ }^{4}$ AbbVie, Ljubljana, Slovenia; ${ }^{5}$ AbbVie, Hod HaSharon, Israel

Background: Adalimumab (ADA) is approved for treatment of Crohn's disease (CD) and ulcerative colitis (UC); therefore, it is postulated that new onset or flare of inflammatory bowel disease (IBD) is a rare occurrence in ADA clinical trials for non-IBD indications.

Objectives: The purpose of this analysis was to determine the rates of IBD adverse events (AEs) in ADA clinical trials, particularly in spondyloarthritis (SpA) patients (pts) who are at higher risk of IBD as a feature of SpA.

Methods: The rates of IBD AEs in 73 phase 2-4 interventional ADA clinical trials in rheumatoid arthritis (RA), polyarticular juvenile idiopathic arthritis (pJIA), pediatric enthesitis-related arthritis, uveitis (non-infectious intermediate, posterior, or pan-uveitis), hidradenitis suppurativa (HS), adult and pediatric psoriasis (Ps), psoriatic arthritis (PsA), non-PsA peripheral SpA (pSpA), non-radiographic axial spondyloarthritis (nr-axSpA), and ankylosing spondylitis (AS) were analyzed (trials in UC, CD, and intestinal Behcet's disease [BD] were excluded). The search criteria for IBD events included the following standardized MedDRA queries preferred terms: inflammatory bowel disease (IBD), ulcerative colitis (UC), Crohn's disease (CD), IBD-not otherwise specified (NOS), and ulcerative proctitis. The incidence rates (IR) for events of IBD (combined new onset and flare) in interventional clinical trials of ADA are reported as events per 100 pt-years (PY). 95\% confidence intervals $(\mathrm{Cl})$ were based on exact Poisson confidence limits. Results: ADA was administered to 23735 pts, representing 36404.6 PY of exposure. Overall, the IR for IBD events in all interventional ADA trials included in this analysis was $0.1 / 100 \mathrm{PY}$ (Table). The rates of IBD events varied across therapeutic indications from $<0.1$ to $0.8 / 100 P Y$. There were no reports of IBD events in pediatric pts. The IR for IBD events in RA, uveitis, $H S$, and Ps trials were $<0.1,0.2,0.4$, and $<0.1 / 100 \mathrm{PY}$. In SpA, the overall rates of IBD were $0.5 / 100$ PY, while the rates were $0,0.8,0.5$, and $0.7 / 100$ PY in PsA, non-PsA pSpA, nr-axSpA, and AS, respectively. 2216 pts with axSpA (AS: 2026, nr-axSpA: 190) were exposed to ADA; in AS, 14 IBD events (7 new onset and 7 flares) were reported in 12 pts (7 new onset and 5 flares), while in nr-axSpA, 2 IBD events were reported in 1 pt (2 flares).

Table. Incidence of IBD events in patients from ADA clinical trials.

\begin{tabular}{|c|c|c|c|}
\hline Indication & $\mathrm{N}$ (PYs) & $\begin{array}{l}\text { All IBD } \\
\text { AEs, } n^{\S}\end{array}$ & $\begin{array}{r}\text { IR/100 PY } \\
(95 \% \mathrm{CI})\end{array}$ \\
\hline All ADA trials ${ }^{\dagger}$ & $23735(36404.6)$ & 40 & $0.1(0.1-0.2)$ \\
\hline Rheumatoid Arthritis & $15152(24813.0)$ & 16 & $<0.1(0.0-0.1)$ \\
\hline Uveitis & $387(538.8)$ & 1 & $0.2(0.0-1.0)$ \\
\hline Hidradenitis suppurativa & $733(836.3)$ & 3 & $0.4(0.1-1.1)$ \\
\hline Psoriasis & $3500(5268.7)$ & 1 & $<0.1(0.0-0.1)$ \\
\hline All $\mathrm{SpA}^{ \pm}$ & 3218 (3919.9) & 19 & $0.5(0.3-0.8)$ \\
\hline PsA & $837(997.5)$ & 0 & $0.0(0.0-0.4)$ \\
\hline Non-PsA pSpA & $165(390.7)$ & 3 & $0.8(0.2-2.2)$ \\
\hline All axSpA? & $2216(2531.7)$ & 16 & $0.6(0.4-1.0)$ \\
\hline$n r-a x S p A$ & $190(412.2)$ & 2 & $0.5(0.1-1.8)$ \\
\hline AS & 2026 (2119.5) & 14 & $0.7(0.4-1.1)$ \\
\hline
\end{tabular}

$\S_{\text {No IBD events were reported in pediatric patients }}$

†All ADA adult and pediatric patients in all interventional studies excluding Crohn's disease, ulcerative colitis, and intestinal Behcet's disease.

${ }_{\text {I }}$ All ADA patients in all interventional studies of PSA, non -PSA pSpA, nr-axSpA, and AS.

?All ADA patients in all interventional studies of $\mathrm{nr}$-axSpA and AS.

Abbreviations: IBD = inflammatory bowel disease; $A D A=$ adalimumab; $P Y=$ patient years;

AEs = adverse events; IR = incidence rates; $\mathrm{Cl}=$ confidence interval; $\mathrm{SpA}=$ spondyloarthritis; PSA $=$ psoriatic arthritis; $p S p A=$ non-PSA peripheral spondyloarthritis; $\operatorname{axSpA}=$ axial spondyloarthritis; $\mathrm{nr}$-axSpA = non-radiographic axSpA; $\mathrm{AS}=$ ankylosing spondylitis.

Conclusions: The rates of IBD AEs in ADA clinical trials were generally low across all indications, with all events occurring in adult pts. In AS pts, who are at increased risk of manifesting IBD, the rates of IBD for pts treated with ADA $(0.7 / 100 \mathrm{PY}[95 \% \mathrm{Cl}, 0.4-1.1])$ were similar to published placebo rates pooled 